\title{
Meconium periorchitis: An incidentally diagnosed rare entity during inguinal herniorraphy
}

\author{
Gül Durmuş ${ }^{1}$, Özlem Boybeyi-Türer ${ }^{1}$, Mina Gharibzadeh-Hizal ${ }^{2}$, Saniye Ekinci ${ }^{1}$, Nural Kiper ${ }^{2}$ \\ ${ }^{1}$ Department of Pediatric Surgery and ${ }^{2}$ Department of Pediatrics, Division of Pediatric Chest Diseases, Hacettepe University, \\ Faculty of Medicine, Ankara, Turkey. E-mail: ozlemboy80@yahoo.com \\ Received: 13th July 2017, Revised: 8th September 2017, Accepted: 23rd September 2017
}

SUMMARY: Durmuş G, Boybeyi-Türer Ö, Gharibzadeh-Hizal M, Ekinci S, Kiper N. Meconium periorchitis: An incidentally diagnosed rare entity during inguinal herniorraphy. Turk J Pediatr 2018; 60: 612-614.

Meconium periorchitis (MPO) is a rare disorder caused by meconium peritonitis with the leakage of meconium into the scrotal sac through the patent processus vaginalis. MPO may be rarely detected during inguinal hernia repair. The association of MPO with cystic fibrosis is rarely seen. We present a male infant with the complaint of left groin swelling, compatible with reducible inguinal hernia. An herniotomy was carried out and the greenish nodules with calcifications were detected. Histopathological examination was compatible with MPO. Two months later the patient was diagnosed with atypical cystic fibrosis. Clinicians should be aware of MPO presentations and its appearance on the hernia sac to prevent unnecessary orchiectomy.

Key words: meconium periorchitis; inguinal hernia; cystic fibrosis.

Meconium is the greenish fetal intestinal content that contains swallowed amniotic fluid, lanugo, pancreatic and intestinal enzymes, bile salts and other cells. ${ }^{1}$ Meconium causes an inflammatory reaction when it spreads into the peritoneal cavity because of an intrauterine intestinal perforation called meconium peritonitis. ${ }^{1,2}$ The leakage of meconium into the scrotal sac through the patent processus vaginalis causes meconium periorchitis (MPO). ${ }^{1}$ Although the association of meconium peritonitis with cystic fibrosis is commonly seen, association of MPO with cystic fibrosis is rarely reported. ${ }^{1,3,4}$

The clinical presentations of MPO are mostly soft scrotal swelling, hard testicular masses and hydrocele. ${ }^{4,5}$ However, the association with as inguinal hernia is extremely rare. Herein, we represent a case admitted with inguinal hernia and incidentally diagnosed as MPO and subsequently diagnosed as atypical cystic fibrosis.

\section{Case Report}

A male neonate was born to a 29 -year-old primigravida mother at 33 weeks with 2,270 gram weight by a cesarean section because of maternal cholestasis. He passed meconium on his first day. He was intubated for breathing problem during his first 4 days. After that, he could self-ventilate. He did not experience any gastrointestinal and respiratory problems after his discharge.

He was admitted to our clinic with a complaint of left groin swelling which grew with crying. The physical examination was compatible with reducible left inguinal hernia. The herniotomy was carried out as soon as possible. Intra operatively greenish small nodules with fine calcifications on the hernia sac were detected. Therefore, we explored the testicle and found an amorphously shaped greenish mass adhering to the testicle (Fig.1). The testicle looked normal. The amorphous shaped mass was excised and the testicle was preserved. Then, a standard herniotomy was carried out. The post-operative course was uneventful and the patient was discharged the same day.

The histopathological examination revealed amorphous shaped fibro connective tissue with focal areas of calcification, bile pigments, mucinous material and macrophages which were compatible with MPO.

After the histopathological examination report was received, we re-evaluated the patient 
regarding his prenatal history and other past clinical history. The prenatal history was unremarkable except a suspicious meconium pseudo cyst in prenatal ultrasound scans. The past medical history was also unremarkable. We performed sweat test to evaluate cystic fibrosis and the results were negative. The abdominal X-ray revealed absence of peritoneal calcifications. Two months later, the patient was admitted to the hospital with complaints of coughing, yellow green sticky intestinal content and weight loss. The laboratory features confirmed "pseudo-Bartter syndrome". The sweat test was performed again and the result was negative. The story of meconium periorchitis, coughing, weight loss and pseudoBartter syndrome were considered as atypical cystic fibrosis, even if the sweat test was negative. The complaints resolved after sodium chloride and pancreatic enzyme replacement therapy. The patient is still under follow up with pancreatic enzyme replacement therapy; uneventfully.

The patient's anonymity is protected and an informed consent has been taken.

\section{Discussion}

Meconium periorchitis (MPO) is a mass like lesion caused by leakage of meconium into the scrotal sac leading to an inflammatory reaction. ${ }^{4}$ MPO was first described in 1953 by Olnick and Hatcher ${ }^{6}$ as an extension of meconium peritonitis into the scrotum via a patent processus vaginalis. MPO can rarely be diagnosed prenatally with fetal ultrasonography. The typical ultrasonographic findings of MPO were defined by Wax et al. ${ }^{7}$ as calcified scrotal masses, fluid collections causing hydrocele and absent blood flow to the scrotal mass in Doppler ultrasonography. Since these findings are hard to be detected, inguinoscrotal hernia, hematoma, paratesticular tumors and testicular torsion should be considered as differential diagnosis ${ }^{7}$.

Postnatal presentation can be asymptomatic or as hydrocele, soft scrotal mass or a hard small mass in scrotum.1,3,4,8 A soft scrotal mass can be seen in almost half of the cases and a hard mass can be seen in three-fourths of the cases ${ }^{4}$. Hydrocele can be seen in approximately $7 \%$ of cases and some of them can be associated with inguinal hernia ${ }^{4}$. Therefore, presentation as inguinal hernia without hydrocele as it was in the present case is extremely rare.

The present case was admitted with complaint of groin swelling and diagnosed as MPO incidentally. The macroscopic appearance was remarkable and similar to the ones reported in the literature.3,5 It seems like an amorphous shaped paratesticular mass, yellowish green in color and mostly has calcifications. Since we diagnosed MPO incidentally, we re-evaluated the patient and performed an abdominal X-ray revealing absence of peritoneal calcifications. In the literature, it was reported that abdominal calcifications may be absent in $10 \%$ of cases. ${ }^{9}$

Although abdominal calcifications can be commonly seen in cases with MPO, symptomatic meconium peritonitis can be seen in about $20 \%$ of cases. ${ }^{4}$ Meconium peritonitis is a common presentation of cystic fibrosis. Almost 25\% of cystic fibrosis cases may present with meconium peritonitis. ${ }^{2,4}$ However, a few of the reported MPO cases were diagnosed as cystic fibrosis (7-9\%).4,7,10 Therefore, MPO cases are less likely to have cystic fibrosis.

As a result of pseudo-Bartter syndrome, this case was diagnosed as atypical cystic fibrosis. Almost $12 \%$ of cystic fibrosis cases may present with pseudo-Bartter syndrome. ${ }^{11}$ The present case was diagnosed as atypical cystic fibrosis regarding his clinical presentation and response to treatment, although the initial screening with the sweat test was negative.

Asymptomatic masses may resolve spontaneously. Therefore, conservative management is commonly suggested if the diagnosis is certain. ${ }^{1}$ However, MPO is diagnosed incidentally during surgery in most cases. ${ }^{3}$ Since it is a rare entity, it is

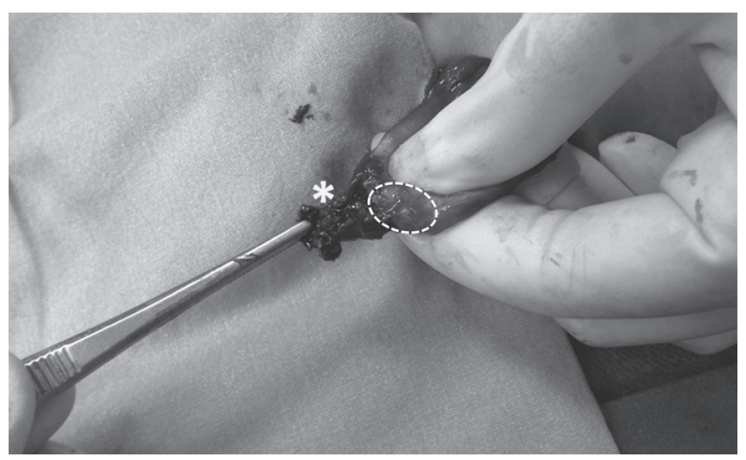

Fig. 1. The amorphous greenish mass $\left({ }^{*}\right)$ adherent to the testicle (dotted circle). 
hard to differentiate MPO from malignant paratesticular tumors ${ }^{12}$ that may lead to end up with orchiectomy in some cases $3,4,13$. It is important to be aware of MPO as a benign cause of a paratesticular mass even in the absence of any significant past medical history in order to avoid unnecessary orchiectomy.

In conclusion, meconium periorchitis should be considered in incidentally detected paratesticular tumors in order to prevent unnecessary orchiectomy. Since MPO may be associated with atypical presentations of cystic fibrosis, cystic fibrosis should be investigated not only with sweat test but also with other clinical and laboratory tests.

\section{REFERENCES}

1. Stupak A, Krzyzanowski A, Semczuk-Sikora A, et al. Conservative management after prenatal ultrasound diagnosis of meconium periorchitis. J Med Ultrason (2001) 2014; 41: 499-505.

2. Ziegler MM. Meconium Ileus. In: Coran AG, Adzick NS, Krummel TM, Laberge JM, Shamberger RC, Caldamone AA (eds). Pediatric Surgery (7th ed). Philadelphia: Mosby-Elsevier, 2012: 1073-1083.

3. Herman TE, Siegel MJ. Meconium periorchitis. J Perinatol 2004; 24: 188-190.

4. Jeanty C, Bircher A, Turner C. Prenatal diagnosis of meconium periorchitis and review of the literature. J Ultrasound Med 2009; 28: 1729-1734.
5. Ekinci S, Karnak I, Akçören Z, Şenocak ME. Inguinal hernia as a rare manifestation of meconium peritonitis: Report of a case. Surg Today 2002; 32: 758-760.

6. Olnick HM, Hatcher MB. Meconium peritonitis. J Am Med Assoc 1953; 152: 582-584.

7. Wax JR, Pinette MG, Cartin A, Blackstone J. Prenatal sonographic diagnosis of meconium periorchitis. J Ultrasound Med 2007; 26: 415-417.

8. Alanbuki AH, Bandi A, Blackford N. Meconium periorchitis: A case report and literature review. Can Urol Assoc J 2013; 7: E495-E498.

9. Varkoni I, Fliegel C, Rosslein R, Jenny P, Ohnacker H. Meconium periorchitis: Case report and literature review. Eur J Pediatr Surg 2000; 10: 404-407.

10. Dehner LP, Scott D, Stocker JT. Meconium periorchitis: A clinicopathologic study of four cases with a review of the literature. Human Pathol 1986; 17: 807-812.

11. Yalçın E, Kiper N, Dogru D, Ozçelik U, Aslan AT. Clinical features and treatment approaches in cystic fibrosis with pseudo-Bartter syndrome. Ann Trop Paediatr 2005; 25: 119-124.

12. Sung T, Riedlinger VFJ, Diamond DA, ChowSolid JS. Extratesticuler masses in children: Radiographic and pathologic correlation. AJR Am J Roentgenol 2006; 186: 487-488.

13. Williams HJ, Abernethy LJ, Losty PD, Kotiloglu E. Meconium periorchitis - A rare cause of a paratesticular mass. Pediatr Radiol 2004; 34: 421-423. 